\section{Investment in Prestige}

Dollars for Research. Science and its Patrons in Nineteenth-Century America. By Howard S. Miller. Pp. $\mathrm{xi}+258$. (University of Washington: Seattle and London, 1970.) \$9.50; $90 s$.

DR MiLleR's book tells us how, in nineteenth century America, the advancement of basic research was often dependent on private philanthropy. Read in conjunction with Hunter Dupree's work on Science in the Federal Government, it helps to clarify certain long term trends in the history of American science.

Before exploring this theme, however, let me make one confession. The more I read of Dollars for Research, the more my interest (and even sympathy) began to shift from those who were receiving the money to those who were giving it. Three or four cases aside, the patrons portrayed here comprise a most extraordinary rogues' gallery of cunning, slightly alienated entrepreneurs. Not a few of them appear to have felt somewhat guilty about their earlier business dealings. Thus they were often easy prey to the argument that, for example, a donation to an observatory would assure them of posterity's favourable judgment. Why? Because such patronage would serve not only to advance scientific knowledge but to boost American prestige as well. Faith in science and the nation, as manifested in good works, would lead to social grace.

Miller, however, does not emphasize this part of the story. Instead, he concentrates on the scientist-salesmen whose initiative lay behind the laboratory boom in the United States, especially in the period $1870-1900$. In the face of often great misunderstanding, these dedicated scholars exhibited great tenacity in the pursuit of funds for their work. Their larger vision was the institutionalization of basic research in universities and research institutes, in contrast to the pattern of Baconian, amateurish science which had prevailed during the earlier part of the century. Clearly they were successful, a fact which the author uses to demonstrate "what a small group with a dynamic programme could accomplish in the political and administrative underworld of scientific enterprise".

Yet the question remains as to what extent the character of the relationship between scientists and their patrons coloured the subsequent history of American science. While Miller does not deal with this point in any detail, his material does make informed specu- lation possible. For instance, the link between appeals based on national prestige and the construction of the world's most expensive scientific apparatus was originally forged in the United States-among other places-during the Jacksonian era. Since then this theme has been realized more fully in America than anywhere else. With so many dollars available for so many telescopes and particle accelerators, is it any wonder that the style of "Big Science" owes historically more to America than to any other country?

Paul Gary Werskey

\section{Between World Tides}

Marine Food Chains. Edited by J. H. Steele. Pp. viii +552 . (Oliver and Boyd: Edinburgh, 1970.) 100s.

Marine Ecology. A Comprehensive, Integrated Treatise on Life in Oceans and Coastal Waters. Volume 1: Environmental Factors, Part 1. Edited by Otto Kinne. Pp. ix +681 . (Wiley Interscience: London and New York, November 1970.) 250s.

BorH these books are edited collections of papers dealing with marine ecology. There the similarity ends. Steele and his contributors take an analytical standpoint; they tackle a specific aspect of ecology-the food web-by considering natural events and processes in populations and ecosystems and then breaking them down into their component parts. At the opposite pole, Kinne and his colleagues start from the physical components of the environment (currents, temperature and light in this volume) and examine the impact of each one in turn on organs and organisms.

Steele's volume consists of the papers given at an international symposium; it leaves a clear impression, as symposia should, of what is not known and, therefore, of the kinds of research we ought to do next. Kinne's book is a collection of articles reviewing what is known; perhaps unintentionally, it leaves the reader with an overwhelming impression of the difficulty of synthesizing our knowledge of the components into an understanding of nature as a whole.

Marine Food Chains consists of twenty-nine papers given at a symposium in Aarhus in July 1968. They are assembled into six sections, each introduced by a distinguished authority in the subject. The titles of the sections illustrate the range: "Recycling of Organic Matter" (introduced by J. D. H. Strickland), "Pelagic Food Chains" (D. H. Cushing), "Feeding Mechanisms"
(C. B. Jørgensen), "Food Abundance and Availability in Relation to Production" (L. M. Dickie) and "Theoretical Problems" (J. H. Steele). There is a summary of the symposium by $\mathrm{L}$. B. Slobodkin but the most effective summary is provided by Cushing's introductory sentence "Any supermarket shows the complexity of the simplest link in a food chain".

Many of the papers deal with the terminal yield of the marine food web and the significance of this in fisheries management. The symposium does not lead to any simple conclusion about the ecological efficiency of the food web; indeed, considerable doubt is cast on the oft-quoted figure of 10 per cent efficiency at each link. It is argued that models of food chains will depend on the recognition and understanding of functional rather than classical taxonomic groups. Variability between groups and regions is likely to be so fundamental that generalized models of wide application are unlikely to be realizable. Further progress will be largely dependent on increased studies of natural populations in the field and, as Slobodkin says, "the quality of work that is done in the field has increased markedly in the last 10 years". Although the papers destroy some of the old ideas about food chains, I agree wholeheartedly with the concluding remark of the book- "the level of sophistication demonstrated by the papers presented in this symposium gives every reason to hope for major intellectual breakthroughs in the future".

It is less easy to pass judgment on Marine Ecology because its 681 pages constitute only the first of three parts which together will form no more than Volume 1 of "Environmental Factors". Four further volumes are planned, and we are warned that some of these will also appear in several parts; they will deal with "Physiological Mechanisms", "Cultivation", "Dynamics" and "Ocean Management".

This first part of Volume 1 contains three chapters, the first being an introduction to oceans and coastal waters as life supporting environments. This is followed by two major chapters dealing with light and temperature (each with five authors). Each chapter is subdivided according to a standard scheme, starting with an introduction and followed by reviews of the responses to light or temperature of (i) bacteria, (ii) fungi and blue-green algae, (iii) plants, (iv) invertebrates and (v) fish. Within each chapter the topics include functional responses, subdivided into tolerance, metabolism, reproduction and distribution; and structural responses 